\title{
Adaptive Mutual Feedback Teaching Mode of Synchronous Online + Asynchronous Online Under COVID-19 Epidemic Situation
}

\author{
Lin Chen ${ }^{1, *}$ \\ ${ }^{1}$ Department of Electro-Mechanics and Information, Chengdu Agricultural College, Chengdu, 611130, China \\ *Corresponding author.Email: 19705522@qq.com
}

\begin{abstract}
The epidemic situation has posed a severe threat to teaching development. Under this background, the use of online teaching encountered various problems, including the lack of information construction hardware conditions, uneven teachers' information teaching level, needing psychological adjustment for teachers and students, insufficient or too much teaching supervision, etc. On the basis of analyzing the problem, the adaptive mutual feedback teaching mode of synchronous online + asynchronous online was put forward to solve the problem. This thesis explained the connotation of the teaching model, the relationship between dynamic adjustment and auxiliary, and the teaching attention points of adopting the model. Finally, it drew the conclusion that the teaching model is an effective way to adapt to the current online teaching situation. Keywords: COVID-19 epidemic situation, Synchronous online, Asynchronous online, Teaching mode
\end{abstract}

\section{INTRODUCTION}

COVID-19 epidemic situation has brought great influence to the life, work and study of the masses, especially the severe problem about whether the schools can start school smoothly and carry out the normal teaching work. Because the traditional teaching mode of offline centralized teaching can't be adopted, the teaching mode based on online teaching has become the response choice of each teaching unit during the epidemic situation. Each university has chosen the platform of Super Star Learning, Cloud Class, Rain Class, Tencent Class, and Ding Talk and so on. Online education, which used to be an auxiliary means of teaching, was estimated that China's online education users are expected to reach 309 million 2020[1]. However, in the process of practice, the uneven network environment and hardware conditions have caused great trouble for teachers and students when teachers carry out online teaching, and the massive teaching resources have brought confusion to teachers and students. Worse still, teaching supervision has become excessive or inferior because of time and space differences and lack of experience. The sudden improvement of information teaching level is a difficult challenge for some teachers, and it is also accompanied by many problems such as teachers and students' psychological transformation in unexpected situations. It is necessary to have a more flexible and effective way to deal with the severe challenges facing online teaching at present.

Before the outbreak of the epidemic situation, Peking University, Zhejiang University, Shanghai Jiaotong University and other major domestic colleges and universities carried out the exploration and practice of $\mathrm{CH}$ -
SPOC, SOPC, MOOC and mixed teaching, mainly focusing on the means and methods of online teaching. After the development of the epidemic situation, a number of teaching research places have been added, including education industry, teaching platform, educational thinking, teaching mode, learning situation analysis, industry opportunities and so on. This thesis mainly put forward the adaptive mutual feedback teaching mode of synchronous online + asynchronous online from the perspective of teaching practice and discussed its connotation and feasibility.

\section{PROBLEMS IN THE PRACTICE OF ONLINE TEACHING}

\subsection{Different regions, different home network environment and hardware facilities development is not equal, and real-time online teaching is not satisfactory}

Online teaching is based on the network as a medium of teaching, so it has high requirements for broadband. M-Lab joint Google, Princeton, and Open Technology Institute data for 2018 show that the global average bandwidth connection speed is $9.1 \mathrm{Mbps}$, and the average broadband speed in China is only $2.38 \mathrm{Mbps}$ [2]. In addition, the development of network construction in China is not balanced, and the construction of network facilities in eastern and western regions, cities and villages are obviously different, including repeated and lacking construction in some areas. Furthermore, according to the 
44th CNNIC China Internet Report, the number of Internet users using mobile phones accounted for $99.1 \%$, the number of desktop computers accounted for $46.2 \%$, and the number of laptop computers connected to the Internet accounted for $36.1 \%[3]$, so the difference in access environment of the network was obvious.

Due to the objective problems of network construction, online teaching has been fully spread out from the end of February, especially after the online live broadcast of the peak time courses in class, teachers and students have encountered a large area of network failures: Super Star Learning, Classroom School, Tencent Classroom, Ding Talk all have different degrees of network delay, or even network paralysis. Each school adopts different ways to solve the problem, such as wrong peak class, or adopt multiple alternative live broadcast platforms, which is unsatisfactory from the actual effect. Moreover, in order to find or use net, teachers and students in the less developed areas such as rural areas made the rural areas troubled and unquiet. Due to the incomplete construction of power facilities, sudden power outages in class time have become difficult for some teachers and students to overcome. In addition, according to the survey, $1 / 3$ to $1 / 2$ of the classes with more rural students have no computers in their homes and only mobile phones can access the Internet, and students face the difficulties of professional courses that require computers to carry out practical operations. The situation that teaching practice cannot be guaranteed synchronously is more prominent in poor areas.

It can be seen that the epidemic situation highlights the short board of the network teaching environment in China, and the construction level of information facilities and equipment needs to be improved urgently.

\subsection{In the face of so many teaching platforms and massive teaching resources, teachers have difficulty in choosing}

In order to ensure the normal operation of teaching, the Ministry of Education has organized 22 online curriculum platforms to open more than 24,000 free online courses[4]. All kinds of teaching demonstration packages and open classes have been introduced in the major online teaching platforms, and the audio and video resources and document resources on the network are numerous, but the construction situation is mixed. Actually, teachers have two puzzles: the one is that the online teaching platform has different advantages and disadvantages, so teachers need to spend a lot of time to adapt to the different platforms of live broadcast and use. Moreover, they must make comparisons and choices in teaching and adjust according to the situation dynamically; the other is that in the face of massive teaching resources, teachers have no way to screen and identify effectively, especially different curriculum categories, different curriculum requirements and different teaching objects, which make curriculum teaching resources individualized.

\subsection{Teaching supervision and supervision have the problems of idealization, of control problems, the effectiveness of supervision is difficult to be guaranteed}

Due to the lack of understanding and management experience of online teaching, some schools have weak supervision or too much supervision over online teaching. Some schools do not go deep into the classroom, and do not observe the online teaching situation, so supervision flow in filling form documents with severe formalism. In order to supervise teachers to complete online teaching, some schools require teachers to provide pictures and text proof of multiple online teaching in the teaching process, and set up multiple teachers' self-certification requirements, but that interfere the rhythm of teachers' normal teaching and disrupt the smooth teaching.

In the way of supervision, there is a lack of methodological innovation and adaptability. Some schools ignore the characteristics of network teaching, lack of investigation and mapping of online teaching situation, copy the program of offline supervision. Worse still, they require teaching time and teaching content must be strictly in accordance with the original plan, so teaching inspection content and the original offline teaching requirements become same. However, some schools put flexibility above the rigor of teaching, which lacks of overall control of the teaching situation.

\subsection{Online teaching, which is highly dependent on the network, requires a high level of information for teachers, and some teachers are at a loss}

The level of information teaching in China mainly exists the imbalance of regional development, the imbalance of discipline development and the imbalance of teachers' development in different ages. In the face of the need for higher level of information literacy, and highly dependent on the network of online teaching, some teachers have technical difficulties and psychological difficulties. Online teaching not only requires teachers to have the basic ability of network teaching resource extraction, teaching document processing, resource picture processing and so on, but also needs to have the ability of timely handling in the face of network teaching emergencies, the ability of integration and construction of online courses, the ability of making teaching resources such as micro-class resources, the ability of mastering and using online teaching platform, etc. In teaching consciousness, we also need to have the ability to integrate information technology with subjects from simply processing teaching resources to creating teaching resources suitable for online learning. Moreover, we should build a teaching evaluation system suitable for online development and data collection, and learn to analyze and reflect on teaching big data. For some teachers who are used to traditional teaching methods or do 
not have information teaching conditions and learning conditions, the threshold of online teaching is difficult to cross.

\subsection{There are psychological adjustment problems in teachers and students under the background of emergency, and the psychological preparation of online teaching mode under the situation of epidemic situation is not enough}

Through online teaching practice, it is found that teachers have different anxiety psychology before class, during class and after class. Before class, there are many problems such as the unforeseen environmental problems, whether there will be some accidental factors, whether there will be a cold field, whether the teaching resources are well prepared, whether the teaching platform is running well, whether the bandwidth meets the needs of online teaching, and how to teach online, such as physical education and practical teaching courses in professional laboratories. During class, there are some worries about how to deal with the sudden network failure, adjust create the classroom atmosphere to realize the good teacher-student interaction, understand the students' current learning situation, and evaluate the teaching. After class, we pay attention to the problems of teaching feedback, teaching data statistics, teaching resources construction of the next course, and some teachers reflect the anxiety phenomenon of insomnia and dreams due to excessive tension.

For students, because the epidemic situation can't go out more depressed mood, so the online learning that needs a high degree of concentration becomes more brainconsuming and is prone to burnout. There is a sense of urgency and anxiety about some learning contents which can't be studied synchronously or directly in practice because of regional restrictions and conditions, and even students have inferiority complex and depression because they do not have information learning conditions.

Both teachers and students need to take advantage of the situation, relieve negative emotions, and face online teaching with positive mood.

\section{ANALYSIS OF TEACHING MODE OF SYNCHRONOUS ONLINE + ASYNCHRONOUS ONLINE}

Because the online teaching is limited by the network situation, the power supply situation, the self-information condition and so on, it is proposed to adopt an adaptive mutual feedback teaching mode of synchronous online + asynchronous online to explore the solution of the problem.

\subsection{What is teaching mode of synchronous online + asynchronous online}

Synchronous online teaching mode is a mode for teachers and students to interact and teach at the same time in different time and space. The mode is used by teachers as sponsors to realize one-to-one or one-to-many synchronous online teaching. It can use mobile phone, computer, tablet and other terminals for real-time interconnection, including video voice, screen delivery, document demonstration and so on, with the characteristics of time synchronization in time and space [5]. Its advantage is to achieve the maximum degree of similar offline teaching synchronization, live broadcast as the course, divided into before class preview, during class learning, after class review, through which the network will be the interaction between teachers and students connected. At present, the mainstream uses Tencent Classroom, Cloud Class, Ding Talk, Honghe online live classroom. All support online teaching process of teacher-student status query and communication interaction, and part of the course playback video is convenient for students to review after class, as well as provides classroom participation data to facilitate teachers to check the data concerning the number of students entering the classroom, online duration, etc.

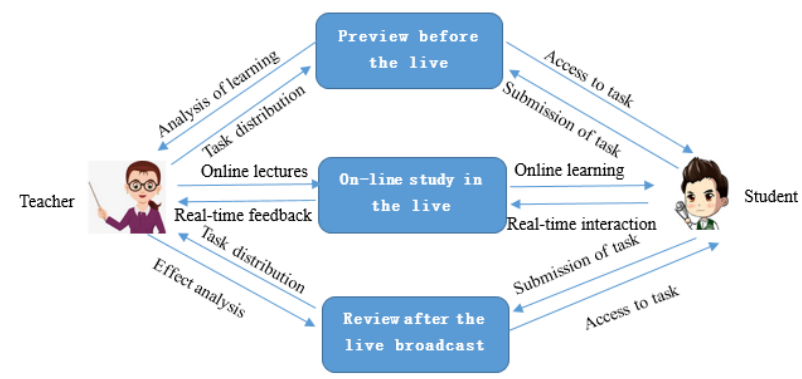

Figure 1. Synchronous online teaching

Asynchronous online teaching mode is the separation of teaching and learning activities in time and space. Teachers can do teaching design, record teaching video and make teaching resources in advance. According to the actual situation, the students adjust the learning time and rhythm adaptively, and complete the learning content and teaching evaluation under the task-driven. Through the teaching platform, teachers and students conduct series of online interactive activities, including discussion, answering questions and evaluating, so as to achieve discussion and the exchange of questions online teaching at different time, or in the form of the flipping classroom at the same time. Taking Super Star Learning as an example, teachers can place abundant teaching resources in the course catalogue and set up examination points in advance, and students can control their own time to browse and study, and record each student's learning situation in the background. At the same time, the platform provides quick class production, supports pictures, videos, PPT, tests and text content, and realizes the mixed production of course recording and multimedia resources. Teachers can record teaching 
content in advance and publish teaching resources through online platform for students to learn at any time.

The advantage of this mode is that it can avoid the difficulty of real-time connection caused by instantaneous network congestion. Teachers and students can adjust the rhythm of teaching and learning adaptively according to their own actual situation. It has the learning characteristics of 4 A (Anyone, Anytime, Anywhere, Anything), which alleviates the psychological tension in the online teaching of teachers and students.

\subsection{Applied way of the mode}

Synchronous online + asynchronous online is a hybrid teaching mode with complementary advantages and flexible adjustment according to teaching situation and learning situation. According to the teaching situation, and different learning situation, for example, in more developed cities. Teachers and students can be guaranteed in the case of information conditions, using synchronous online as the main live teaching and regarding asynchronous online as a supplement after-class online answering questions and so on. If in less developed areas, teaching can be asynchronous online, and avoid the peak use of the network to carry out teaching activities. Teachers should have clear teaching design, teaching tasks, teaching resources, recording teaching videos, and issuing requirements in advance through the platform. In class, we can use forums, online answering questions, homework display, online evaluation to encourage students to invest in learning and maintain learning status. For the complex learning situation and the complex students, the auxiliary relationship of synchronous online + asynchronous online can be dynamically adjusted according to the actual situation. For example, the teaching class students in colleges and universities are scattered, and the network situation is complex. Some students are in the urban environment, but some students are in the rural and even remote mountain areas. Thus, some students can't follow up in real time when make full use of synchronous online teaching. After online teaching, the current teaching platform provides teaching playback, and can distribute after-class related video links for students to review or relearn. Besides, we can make teaching PPT, micro-class, speed class in advance, and set up task assessment points, online tests, online message boards and so on in the learning content.. On the one hand, it promotes students to learn independently. On the other hand, it checks and masters students' learning situation and big data. Teachers can adjust the teaching progress and teaching methods according to the big data in learning situation. Moreover, students can carry out online learning according to their own actual situation, and select the teaching contents that need to be grasped or not mastered in the rich online teaching resources, so as to achieve adaptive learning.

\subsection{Teaching attention points for using the mode}

For teachers, teaching design should be carried out before online teaching, and task-driven should run through teaching all the time, so that to ensure the clarity of task points. In addition, language habits and teaching activities should be close to the network usage habits of contemporary students. Teachers should change their roles, and do a good job of active atmosphere teaching anchor, teaching process guide, teaching framework designer.

For students, it is necessary to emphasize the cultivation of autonomous learning ability, strengthen the internal motivation of learning, take the initiative to participate in teaching activities and do not idle away their lives.

For the school, it is very important to find out the teacher's situation and the student's situation, encourage the teacher to carry out the online teaching activities according to the local conditions, and endow the teaching with appropriate flexibility, making a variety of management plan plan while strictly managing so that to avoid rigidity and formalization.

\section{CONCLUSION}

The development of teaching in the epidemic situation requires the cooperation of school-teacher-student and the change of thinking. Although the lack of experience for most teachers can be used for reference, which puts forward higher requirements for their own level of information teaching, challenges and opportunities coexist, and the epidemic situation has given birth to teachers' thinking informatization 2.0. In teaching practice, teachers actively or passively improve the level of information teaching to adapt to the new situation. In the teaching, the adaptive mutual feedback teaching mode of synchronous online + asynchronous online has been put into practice, and a rich online teaching resource real-time online teaching environment has been created. Practice has proved that this mode is an effective way to deal with major emergencies, including epidemic situation, which is worth thinking and popularizing.

\section{ACKNOWLEDGMENT}

This work was supported by

1) Chengdu Agricultural Science and Technology Vocational College 2020 Research Project (No.20JY203)

2) Sichuan Philosophy and Social Science Research Base-Sichuan Teacher Education Research Center Funded Project (No.TER2018-019).

\section{REFERENCES}

[1] Fu Weidong, Zhou Hongyu. Challenges and Countermeasures of the COVID-19 brought to China's Online Education[J]. Journal of Hebei Normal University 2020, 22 (2):14-18. 
[2] Tencent. 2018 Global Average Bandwidth: China is Less Than A Tenth of South Korea's[EB/OL].

https://new.qq.com/omn/20180711/20180711A10HT4.h tml,2018-7-11.

[3] China Network Internet Information Center. China's Internet Development Statistics Report[R]. State

Internet Information Office of the People's Republic of China: China Internet Information Center, 2019.
[4] Baidu. China Online Education Market Development Status Online Education EB/OL].2020https://baijiahao.baidu.com/s?id=1658231 $410478755895 \&$ wfrid=spider \&forid=pc, 2020-2-11.

[5] Yu Shengquan, 360 doc Personal Library. 10 Modes And Support Tools For Online Education [EB/OL]. http://www.360doc.com/content/20/0220/14/30898787_ 893395755.shtml,2020-2-20. 